\title{
Evaluation of Mobile Based Advisory Services on Agri and Allied Sectors in Adilabad District
}

\author{
Y. Praveen Kumar*, G. Shivacharan, M. Raghuveer, A. Poshadri, \\ M. Sunil Kumar and A. Ramadevi
}

Krishi Vigyan Kendra, PJTSAU, Adilabad, India

*Corresponding author

\section{A B S T R A C T}

\begin{tabular}{|l|}
\hline Ke y w o r d s \\
AKPS, Relevancy, \\
Timelines and \\
Accuracy
\end{tabular}

Interactive Information Dissemination System (IIDS) - Annapurna Krishi Prasar Seva (AKPS) is a mobile based agro advisory service from Professor Jayashankar Telangana State Agricultural University (PJTSAU). Registered farmers receive text messages and can contact with experts to solve their queries using its toll free number 18004253141 . The present study conducted by Krishi Vigyan Kendra, Adilabad to evaluate mobile based advisory services on agri and allied sectors in the district with a sample of 120 farmers during 2018-19 to 2019-20. The study found high relevancy (57.50\%), high timelines $(71.67 \%)$, high accuracy $(60.00 \%)$, high knowledge levels $(48.33 \%)$ and medium adoption $(42.50 \%)$ of the advisories. The advisories sent through AKPS were accessible, adoptable and useful to the farmers because the advisories were mostly need based, problem solving and preventive in nature.

\section{Introduction}

Information and Communication Technology (ICT) plays an important role in dissemination of information from source to receiver. Mobile phone technology has rapidly extended its roots all over the world. In developing countries like India mobile phone usage is on increasing trend. As per the Telecom Statistics India, 2019, number of mobile phone connections in country is 1161.71 million with an overall teledensity (No. of connections per 100 households) of 90.10 . Teledensity in the rural India is $\mathbf{5 7 . 5 0}$ and in urban it is 159.66 .
India having 636.73 million internet subscribers of which 35.65 per cent resides in rural areas. State of Andhra Pradesh (Erstwhile) having 88.17 millions of telecom subscribers among which 42.24 million in rural area and 45.93 million in urban area with a teledensity of 97.55 of which 64.96 in rural area 181.15 in urban area. (Source: Telecom statistics India, 2019)

Agriculture is the primary source of livelihood for about 58 per cent of India's population. India stands at $10^{\text {th }}$ place in the world in arable land resources possessing 46 of the 60 soil types. India is the largest producer of spices, pulses, milk, tea, cashew 
and jute; and the second largest producer of wheat, rice, fruits and vegetables, sugarcane, cotton and oilseeds. (Source: https://www.ibef.org/industry/agriculturepresentation)

Adilabad is one of the districts inhabited by highest number of tribal people in Telangana state of India with more than $75 \%$ rural population and among them $35 \%$ of people are tribes. Majority of the farmers are marginal and small accounting to $67.8 \%$ of total land holdings in the district (Poshadri et $a l ., 2019)$. In total gross cropped area of the district, pulses, soybean and cotton occupy $18 \%, 12 \%$ and $77 \%$ area respectively (Directorate of Economic and Statistics, 2016-17).

The data usage of Indian shows the strength of internet penetration in rural India and ample opportunities to connect farming community. Connecting farmers using mobile phone plays an important role in dissemination of information among the rural areas of India. Different studies showed that general application of mobile phones has improved the standard of living of the poor farmers in developed nations.

There are many possibilities of integration of mobile phones in agriculture for the overall agriculture and rural development. Mobile phones which are normally in use to communicate with family and friends could be used for agriculture. Mobile phone services focusing on Farmer centric SMS services, weather alerts, improving know how knowledge of the farmers, accessing agriculture market information which helps in taking better decisions at farmer's level.

Providing Timely, reliable and accurate information for the farmers with respect to crop protection, production, weather and market plays a major role in field level decision making.
Interactive Information Dissemination System (IIDS) - Annapurna Krishi Prasar Seva (AKPS) is a mobile agro advisory service offered to farmers by PJTSAU. Registered farmers receive text and voice messages on their mobile phone through AKPS portal. Farmers can directly contact with experts and solve their queries using toll free number 18004253141 .

The agro advisories sending by KVK, Adilabad scientists were based on contemporary agricultural issues in the district viz., Pest and diseases management in agriculture and horticultural crops, fertilizer management, weed management, others. This project has been started in the year 2014 and running successfully till date. There are 1914 farmers registered with KVK, Adilabad, under this project covering 224 villages of 23 mandals across erstwhile Adilabad district.

Madan et al., (2015) in their study on Constraints faced in mobile based agroadvisory services and strategy for enhancing the effectiveness of mKRISHI® found that the most severe constraint in the functioning of mKRISHI ${ }^{\circledR}$ was Lack of updated information followed by High cost for service provided, low IT literacy and low literacy.

Ram et al., (2015) Concluded that information gathered through agro advisory services has been very useful and helpful and farmers started taking interest in accessing information on agriculture and animal husbandry.

Reddy et al., (2017) in their study on Perception and Usefulness of Mobile Phone Based Agro-Advisories (MBAs) found 48.33 per cent of respondents indicated as mobile phone based agro-advisories were moderately useful and the majority (50.00\%) of the respondents had positive perception towards the mobile phone based agro-advisories. 
Jadhav et al., (2018) expressed that timely dissemination of these advisories/contingency crop plans/measures will help the farmers to maximize the yield by optimum use of inputs and enhance the economic returns of the farmers.

Lakshmi et al., (2018) found in their study on Impact of Annapurna Krishi Prasara Seva (AKPS) Agro Advisory Services in East Coastal Districts of Andhra Pradesh that majority of the respondents have moderately favorable attitude (44.16\%) towards AKPS agro advisory service where the messages were partially understandable (41.66\%), needful $(83.33 \%)$, timely $(53.33 \%)$, saves time\& money $(83.33 \%)$, increase in knowledge $(79.16 \%)$, increase productivity (83.33\%), information can be adoptable in field conditions (43.33\%), AKPS is a boon to the farming community $(60.83 \%)$.

Soumya et al., (2018) found in their study on Usefulness of agro advisories disseminated through interactive information dissemination system (Annapurna Krishi Prasar Seva) in the state of Telangana that majority i.e., 53.34 percent of the respondents were getting highly relevant advisories, 49.17 percent of the respondents were reading the advisories easily, 42.50 percent of the respondents were getting the advisories with adequate content without missing any information and 40.00 percent of respondents were said that given advisories were most useful.

\section{Materials and Methods}

Ex-post facto research design and simple random sampling followed. Data collected using Semi structured interview schedule, Focused group discussions and Google forms. A total of 120 farmers in 2018-19 interviewed and discussed with. Descriptive statistics used for distribution of respondents against each category.

\section{Objectives}

To study the relevance of the advisories sent through AKPS

To reveal the timeliness of the advisories sent through AKPS.

To find out the accuracy of the advisories sent through AKPS.

To identify the level of knowledge of the registered farmers on advisories sent through AKPS.

To assess the extent of adoption of advisories sent through AKPS by the registered farmers

To elicit the constraints and suggestions from the discontinued and continuous callers for improving mobile agro-advisories system of AKPS.

\section{Results and Discussion}

In the year 2018-19 and 2019-20, 77 and 115 agro advisories sent to the registered farmers addressing the contemporary issues in agriculture.

\section{Total no. of farmers registered 1914 \\ 2 No. of farmers registered in 2018-19 321 \\ 3 No. of farmers registered in 2019-20 204}

District covers with Cotton, Soybean and Red gram during kharif and Bengal gram rabi. Most of the advisories sent related to crop protection based on field diagnostic visits. Advisories related to food and nutrition also sent during 2019-20 to address malnutrition in the district.

The advisories sent covering Pest and diseases management in agriculture and horticultural crops, fertilizer management, weed management, information about Govt. schemes etc. the relevancy of the advisories found high $(57.50 \%)$ followed by medium (31.67\%) and low (10.83\%). The reason could be that the advisories sent by KVK, Scientists 
were based on field visit observations and precautionary measures in order to manage pest and diseases in major crops.

The above findings were in partial confirmation with the findings of Laksmi et al., (2018) and Soumya et al., (2018).

Majority (71.67\%) of the farmers felt that the advisories sent were timely and matching with field level problems followed by medium (20.00\%) and low (8.33\%). Most of the crop protection advisories sent in advance as a precautionary measure. The above findings were in partial confirmation with the findings of Laksmi et al., (2018) and Soumya et al., (2018).

Majority $(60.00 \%)$ of the farmers felt that the advisories sent were highly accurate followed by medium (23.33\%) and low (16.67\%).
Farmers expressed the advisories sent were accurate in terms of damage symptoms, pest name, suggested chemical name and its dosage. The above findings were in partial confirmation with the findings of Laksmi et al., (2018) and Soumya et al., (2018).

From the study it is evident that most $(48.33 \%)$ of the farmers having high knowledge in terms of sent advisories followed by medium (29.17\%) and low $(22.50 \%)$. Frequent sending of advisories made farmers to aware about the pest and diseases and its control measures. Advisories on pink bollworm management and pod borer in red gram imparted knowledge among farmers.

The above findings were in partial confirmation with the findings of Laksmi et al., (2018) and Soumya et al., (2018).

Table.1 Distribution of services based on discipline in the year 2018-19 and 2019-20

\begin{tabular}{|l|l|c|c|}
\hline S. No. & Discipline & No. of advisories in 2018-19 & No. of Advisories in 2019-20 \\
\hline 1. & Crop protection & 35 & 43 \\
\hline 2. & Crop production & 14 & 16 \\
\hline 3. & Horticulture crops & 23 & 19 \\
\hline 4. & Others & 5 & 37 \\
\hline & Total & 77 & 115 \\
\hline
\end{tabular}

Table. 2 Timeliness $\mathrm{N}=120$

\begin{tabular}{|l|c|c|}
\hline Category & Frequency & Percentage (\%) \\
\hline Low & 10 & 8.33 \\
\hline Medium & 24 & 20.00 \\
\hline High & 86 & 71.67 \\
\hline Total & 120 & 100 \\
\hline
\end{tabular}

Table.3 Accuracy $\mathrm{N}=120$

\begin{tabular}{|l|c|c|}
\hline \multicolumn{1}{|c|}{ Category } & Frequency & Percentage (\%) \\
\hline Low & 20 & 16.67 \\
\hline Medium & 28 & 23.33 \\
\hline High & 72 & 60.00 \\
\hline Total & 120 & 100 \\
\hline
\end{tabular}


Table.4 Level of Knowledge N=120

\begin{tabular}{|l|c|c|}
\hline Category & Frequency & Percentage (\%) \\
\hline Low & 27 & 22.50 \\
\hline Medium & 35 & 29.17 \\
\hline High & 58 & 48.33 \\
\hline Total & 120 & 100.00 \\
\hline
\end{tabular}

Table.5 Extent of Adoption N=120

\begin{tabular}{|l|c|c|}
\hline Category & Frequency & Percentage (\%) \\
\hline Low & 26 & 21.67 \\
\hline Medium & 51 & 42.50 \\
\hline High & 43 & 35.83 \\
\hline Total & 120 & 100 \\
\hline
\end{tabular}

From the study it is evident that most $(42.50 \%)$ of the farmers having medium or partial level of adoption of agro advisories sent through AKPS followed by high $(35.83 \%)$ and low $(21.67 \%)$. The reason could be that the suggested chemicals may not be available at local markets or farmers end. Farmers also confusing with the chemical name vs trade name. Farmers also spraying mixed chemicals or chemicals with combined insecticides.

The above findings were in partial confirmation with the findings of Laksmi et al., (2018) and Soumya et al., (2018).

\section{Problems}

The suggested chemicals may not available in rural markets.

Confusion in finding appropriate chemical due to different trade names.

Majority of the farmers sourcing pesticides on credit basis, so retailer selling the chemicals which were available at his shop.

Some of the symptoms were not clear to understand.

Some of the messages were not compatible with their cropping systems.

\section{Suggestions}

Farmers suggested to advice mixed chemicals.

More number of messages on weather alerts need to be sent. (Presently KVK, Adilabad is sending weather alerts to the farmers from District Agromet Unit (DAMU) recieving medium range weather forecast).

More number of messages on market information needs to be sent.

In conclusion from the study it could be concluded that the advisories sent through AKPS were useful to the farmers because the advisories were mostly need based, problem solving and preventive in nature. The text messages sent were acting as reminder and alert the farmers for performing farming practices. Number of active farmers or callers dropping off due to other alternate interactive digital platforms like agriculture mobile apps and whatsapp, where farmers can share digital content.

\section{References}

Agriculture and allied profile. 2019. 
https://www.ibef.org/industry/agriculturepresentation

Jadhav, B. T., Jadhav, J. D., Shinde, V. A., Pawar, P. B., Londhe, V. M. and Amrutsagar, V.M. 2018. Agro advisories a boon for crop planning. Contemporary Research in India. PSAR: 105-110.

Lakshmi S. B., Banerjee, P. K. Punnarao, P and Anurag, T. S. 2018. Impact of Annapurna Krishi Prasara Seva (AKPS) Agro Advisory Services in East Coastal Districts of Andhra Pradesh. International Journal of Agricultural Science and Research. 8(4): 49-58.

Madan, S, Burman, R.R., Sharma, J.P., Sangeetha, V and Iquebal, M.A. 2015. Constraints Faced in Mobile Based AgroAdvisory Services and Strategy for Enhancing the Effectiveness of mKRISHI®. Indian Research Journal of Extension Education. 15 (2): 119-122.

A. Poshadri, Y. Praveen Kumar, G. Shiva Charan, M. Raghuveer, M. Sunil Kumar and A. Rama Devi (2019). Energy Rich Composite Millet and Soybean based Malted Weaning Mix: A Complementary Food in Tribal Areas of Adilabad District, India. Int.J.Curr.Microbiol.App.Sci 8(2):
2058-2064.

Ram, S., Willey, S., Feroze, S.M., Devarani, L., Lala, I.P.R., Singh, A.K., Singh, N.J and Anurag, T.S. 2015. Impact of Mobile based agro advisory: A case study of Tribal farmers of Ri-Bhoi district of Meghalaya. Agricultural Economics Research Review. 28: 183-187.

Reddy, M.M.K, Rao, I.S, Srinivasulu, M and Kumar, G.D.S. 2017. Perception and Usefulness of Mobile Phone Based AgroAdvisories (MBAs). International Journal of Current Microbiology and Applied Sciences. 6(7): 866-872.

Soumya, B., Savitha, B and Rao, I.S. 2018. Usefulness of agro advisories disseminated through interactive information dissemination system (Annapurna Krishi Prasar Seva) in the state of Telangana. International Journal of Agriculture Sciences. 10(16): 7006-7007.

Telecom statistics India. 2019. Economics Research Unit, Department of Telecommunications, Ministry of Communications, Government of India, New Delhi.

\section{How to cite this article:}

Praveen Kumar, Y., G. Shivacharan, M. Raghuveer, A. Poshadri, M. Sunil Kumar and Ramadevi, A. 2020. Evaluation of Mobile Based Advisory Services on Agri and Allied Sectors in Adilabad District. Int.J.Curr.Microbiol.App.Sci. 9(07): 1191-1196. doi: https://doi.org/10.20546/ijcmas.2020.907.137 